\title{
54
}

\section{The delivery of Information Technology capability in secondary schools in England and Wales}

Ian Selwood

The University of Birmingham

Birmingham

United Kingdom
Dave Jenkinson

Stoke Park School and

Community College

Coventry

United Kingdom

\begin{abstract}
In 1990 the introduction of a National Curriculum for England and Wales gave all pupils attending state schools a statutory entitlement to an Information Technology (IT) capability. This paper briefly examines the background to this reform and discusses five models for delivering this capability. The second part of the paper reports on a piece of research which examines how schools have organized their curriculum to meet this legal requirement. Various aspects of the delivery of IT capability are examined including resources, the existence of timetabled IT lessons and which subjects take responsibility for parts of the IT curriculum, together with satisfaction with the present arrangements. The research for this paper was conducted prior to the publication of consultative documents concerned with revising the National Curriculum and the conclusions of the paper consider some of the implications of the proposed changes with respect to the research findings.
\end{abstract}

Main conference themes: information technology, national policies, resources

Educational areas: secondary education

Study topics:

Secondary keywords: curriculum policies, learning models, research 


\section{INTRODUCTION}

The thinking underpinning the development of Information Technology (IT) in the curriculum in England and Wales has, in the main, been from two aspects: 'the development of IT capability; the use of IT to support teaching and learning.' [1, p. 3]

When the Education Reform Act [2] introduced a National Curriculum to England and Wales, one of its many provisions was the introduction of a statutory entitlement to an information technology capability for all children. 'Attainment target and statements of attainment for information technology capability' (AT5) together with 'Programmes of study for information technology capability' were defined in 'Technology in the National Curriculum' [3]. In common with the rest of the National Curriculum, the manner of delivery was left to the schools.

Even though there was no compulsion to deliver IT capability through other subjects, 'Technology Non-Statutory Guidance - Information Technology Capability' [4] advised that: 'The information technology programmes of study are best taught through other subjects' (page C2).

A survey by Passey and Ridgeway [5] found that over $80 \%$ of IT coordinators intended to deliver IT capability across the curriculum. However, this approach to IT in education, taken with the content defined in the National Curriculum [3] implies that all teachers must not only be teachers of their own subject but also teachers of IT.

This paper therefore examines briefly some models of the delivery of IT capability; and reports on a survey which set out to examine how this information technology capability was being delivered in secondary schools in England and Wales. It does not, except in passing, examine the use of IT to enhance teaching and learning.

\section{MODES OF DELIVERY.}

IT capability, as defined in 'Technology in the National Curriculum', [3] can be delivered in a number of ways and the choice of delivery model is dependent upon several issues:

- the existing staff expertise;

- the resources available;

- the current climate regarding assessment.

Mike Smith [6] expanded on the commonly held myth that only two models of delivery of IT capability exists: the isolated subject model and the fully 
permeated model. Five possible models, based on some unpublished work by Passey and Ridgeway [7], are presented here.

\section{Model A: Delivery of IT capability through specialist IT lessons}

In this model IT is considered as a discrete subject; all five strands [4] are delivered and assessed through specialist IT lessons. (Henceforth in this paper the term IT lesson(s) will be used to mean specialist lessons in IT appearing on the school timetable). The advantages of this method are that continuity, progression and assessment are all easily managed, and the method can be used in schools where:

- Few teachers have the competence or confidence to deliver IT capability through their specialist subjects.

- The hardware and software resources are limited in either the number of machines available or the number of IT rooms which can be used.

Disadvantages of this method are likely to be:

- Sufficient IT teachers to deliver IT capability to all pupils are not available.

- Lack of time available within IT lessons to cover the whole IT curriculum.

- IT lessons may take up too much time in an already overcrowded timetable.

- The experience offered to pupils can lack context.

- IT is not used elsewhere in the curriculum to enhance teaching and learning as 'IT is done in IT lessons'.

- IT staff may have little time to promote the use of IT to enhance teaching and learning.

\section{Model B: Delivery of IT capability entirely through subjects across the curriculum}

In this model there are no IT lessons whatsoever. IT teachers are used to support departments in the planning and delivery of lessons involving IT, and with staff development. There will be a clear plan needed for the delivery of each part of the IT curriculum, possibly by mapping IT capability onto the other curriculum subjects. All staff will need a fair degree of competence in, and knowledge about, IT. Variations can include what Smith [6] describes as his 'Principal Host Subject Model (PHS)' and 'Host Subject Year on Year Model (HSY)'. In the PHS model each strand is made the prime responsibility of one subject department. The HSY model is similar to the PHS, but attempts to alleviate the problems of shortage of teacher IT skills by still giving the responsibility of a strand to a subject, but only for one particular year group. 
Advantages of model $\mathrm{B}$ are:

- IT will be used to enhance teaching and learning, as well as delivering IT capability.

- Schools with only a small number of IT teachers, but with staff in a number of curriculum areas willing to explore IT, can deliver the IT curriculum.

- IT capability can be delivered in a more meaningful context as the tasks which students are set, can be related to the subjects being studied.

- The time should be available to deliver IT capability fully; and effective use of the hardware and software spread across subject departments can be made.

Disadvantages are mainly associated with the logistics of organizing this approach, and include:

- The problems of ensuring continuity and progression of pupil experience.

- Coordination of assessment when large numbers of teachers are involved, could be problematic and may be disjointed across the different subject departments requiring extensive moderation procedures.

- Staff expertise may be limited especially when delivering the higher levels of IT capability, leaving the support system under stress.

- IT staff supporting other teachers is costly, as it amounts to two teachers with one class.

Model C: Delivery of IT capability through subjects and IT lesson support This is a mixture of models A and B. Subjects deliver all five strands of IT but there is also some time devoted to IT lessons to deliver say basic generic skills and/or more complex areas of IT capability, and also to pull together experiences gained from using IT across the curriculum. There will still be a need for a clear plan of delivery for each part of the IT curriculum using mapping, or Smith's PHS or HSY models, as well as an IT competent subject staff, since it is unlikely that there will be much, if any, support from IT specialists for subject teachers in this model. However, the advantages are:

- Assessment can be simplified by using IT lessons to moderate subject departments judgements.

- IT can still be delivered in context.

- All five strands are covered with some continuity.

Disadvantages can be similar to model A and model B approaches, but are mainly related to resources, both in terms of hardware required to support this 
model and the demands on IT staff who are needed for IT lessons, and coordinating and supporting IT the work across the curriculum.

Model D: Delivery of IT capability through mapped subject activities and Personal and Social Education (PSE) support

In this model IT is delivered through agreed specific activities being carried out in subject departments with perhaps some IT lessons. Additionally, IT staff give support to form tutors in assessing evidence of pupil IT work and some PSE (Personal and Social Education) lessons are used to consider progression and coherence of IT activities. The major advantage of this model lies in the assessment and recording of IT capability. IT teachers consider assessment of IT capability with form tutors in form time. Form tutors will audit all pupils initially. Assessment decisions are based on this and on assessments of subject activities which occur throughout the year. This information is given to PSE staff who regularly consider attainment of IT capability.

Advantages and disadvantages of this approach are similar to models B and $\mathrm{C}$ depending on whether IT lessons are used or not, but assessment problems are reduced at the expense of more time being devoted by all staff especially those involved in PSE.

\section{Model E: Delivery of IT capability through IT lessons with support from subject departments}

In this model the pupils attend IT lessons and these lessons are regularly visited by subject staff who bring their own expertise and allow IT to be learnt in context.

The advantages and disadvantages of this approach are self evident having considered models A to $\mathrm{C}$.

\section{THE SURVEY}

After initial piloting, a survey, concerning the delivery of IT capability in a sample of 150 secondary schools, was conducted in April 1984. A questionnaire was circulated to IT coordinators in $33 \%$ of the secondary schools situated in the West Midlands of England and 81 (54\%) responses were obtained. The respondents included schools in urban and rural areas, Local Education Authority (LEA) maintained schools, schools funded directly by the Department for Education (DFE), Grant Maintained Schools, schools which are fee paying and selfmanaging, and Independent Schools (not bound by the National Curriculum). 
The survey was designed to identify:

- The type of school and the organization and availability of resources in that school (including staff).

- The organisation of the IT curriculum with respect to the existence of IT lessons and which subjects take responsibility for parts of the IT curriculum.

- The satisfaction with the present arrangements.

\section{Results}

\section{The Schools and their Resources}

Of the 81 replies 60 (74\%) were from LEA schools, 19 (23\%) from Grant Maintained, 1 (1\%) Independent school, 1 (1\%) City Technology College (CTC). The mean number of students in the schools was 834. In examining resources, hardware and human, the CTC has been excluded from the calculations due to its unusual situation concerning funding and ethos. The mean number of pupils per computer in the schools sampled was 16. This figure does conceal very wide variations. The mean number of IT teachers was found to be 1.86 , but it was not uncommon for the schools to have only one IT teacher. The comparable figures for the CTC are 240 computers on site giving a pupil:computer ratio of 5:2 with 10 IT teachers.

\section{IT Lessons}

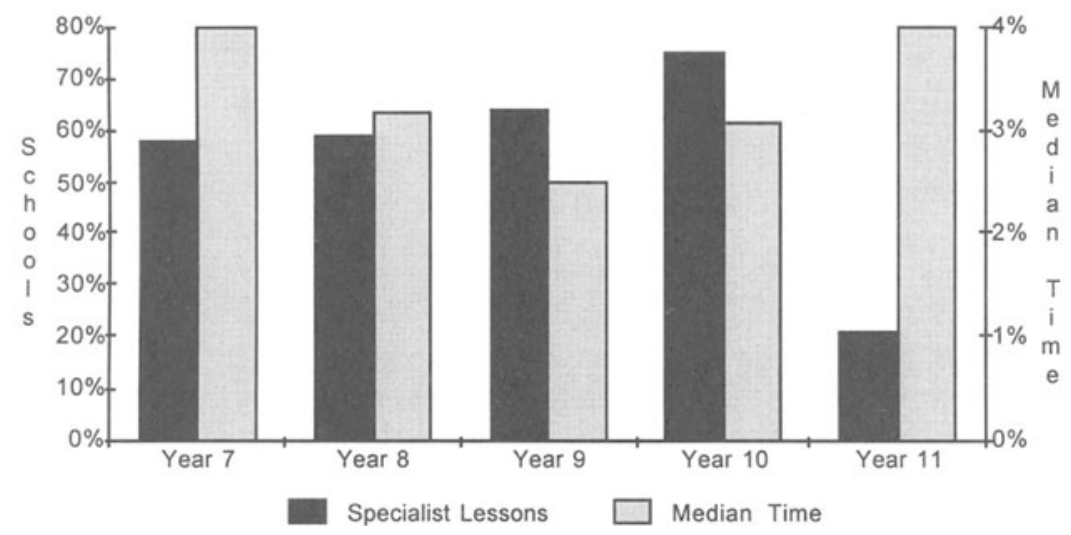

Fig. 1 Schools delivering IT capability in IT lessons by years, and median percentage time of the overall school week spent in IT lessons. 
Surprisingly the number of schools which have IT lessons, steadily increases through the first four years and drastically drops for year 11 (fig. 1). However, the trend for the median amount of time spent in IT lessons starts high (4\%) in year 7 (approximately 1 lesson per week in a 25 period week) down to $2.5 \%$ (approximately 1 lesson per fortnight in a 20 period week) in year 9 . In year 10 and 11 it gradually increases back up to $4 \%$.

\section{IT Across the Curriculum}

The data displayed in Fig. 1 also indicates what percentage of schools must rely totally on IT capability being delivered across the curriculum, broken down into year groups. This is shown in Table 1 below.

Table 1 Schools not having IT lessons by year group

\begin{tabular}{llllll}
\hline Year Group & 7 & 8 & 9 & 10 & 11 \\
Schools not having IT lessons. & $4 \%$ & $4 \%$ & $3 \%$ & $2 \%$ & $79 \%$ \\
\hline
\end{tabular}

Models of Delivery of IT.

The IT coordinators were asked to choose a model of delivery which was the closest fit to their school's mode of delivery. The five models detailed above were outlined for them to choose from.

Table 2 Models of delivery used, shown as a percentage of schools responding

\begin{tabular}{lllll}
\hline Model A & Model B & Model C & Model D & Model E \\
$15 \%$ & $17 \%$ & $35 \%$ & $7 \%$ & $26 \%$ \\
\hline
\end{tabular}

It is apparent from Table 2 that $59 \%$ (models B, C and D) of the schools deliver some IT capability through curriculum subjects, but only $17 \%$ (model B) used this as the sole method for delivering IT capability. Also, whilst $76 \%$ (A, C and E) of schools used IT lessons, only $15 \%$ (model A) used them without the involvement of other subjects. Comparing Table 2 with Fig. 1 or Table 1, it is clear that IT lessons were felt appropriate in a majority of cases but when IT lessons are timetabled varies across the sample.

\section{Subject Departments Responsible for Delivering IT}

The following graph, Fig. 2, shows which subject areas take on some responsibility for delivering IT capability in the schools surveyed. Not surprisingly, IT coordinators reported the core subjects of the National Curriculum, Mathematics, English and Science, together with Technology taking on the major responsibility. 


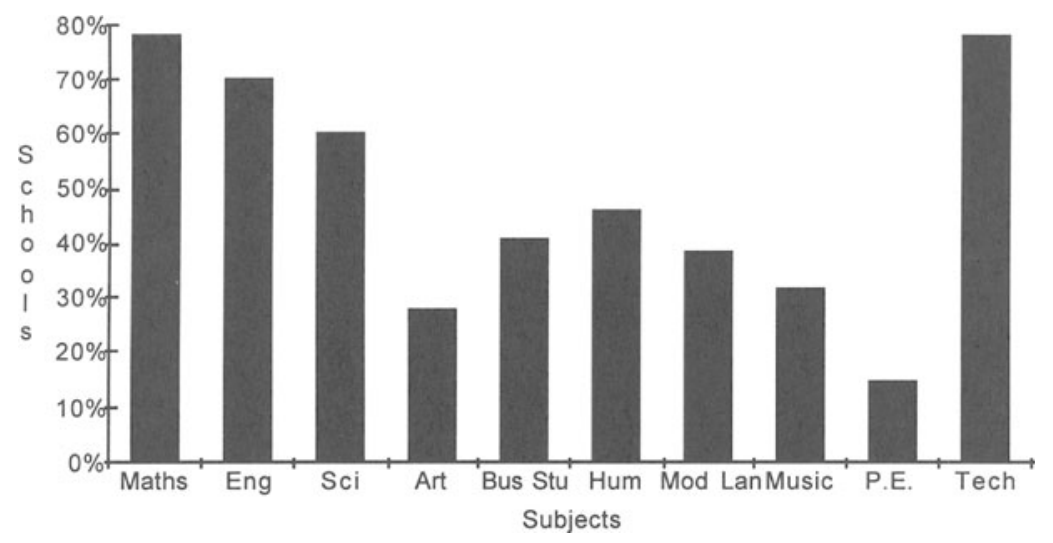

Fig. 2 Schools delivering IT through curriculum subjects

However, when the respondents were asked if they felt that the subject areas delivered IT capability adequately, the results in Fig. 3 were obtained.

Further analysis of Fig. 3 highlights a major concern. $91 \%$ of IT coordinators reported dissatisfaction with the way IT capability is delivered by subject departments. The picture was not so bleak concerning the other aspect of IT in Education, namely the use IT by subjects to enhance teaching and learning. In response to the one question concerning this aspect of IT, $70 \%$ felt that IT was being used to enhance teaching and learning in the subject areas, with only $15 \%$ responding it was not.

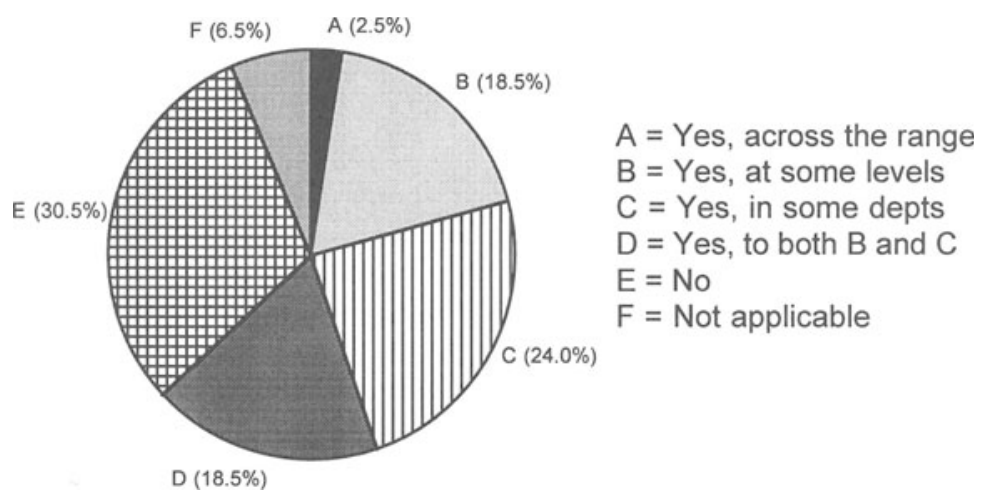

Fig. 3 Respondents' satisfaction with delivery through subjects 
Time for IT Lessons

Asked if they would like to increase the amount of time pupils spent in IT lessons, a majority of over 2:1 was in favour of this. The average time which was suggested being approximately equal to one lesson per week in a twenty period week, in each year of secondary education.

\section{CONCLUSIONS AND RESERVATIONS.}

When Passey and Ridgway [7] presented their five models with variations for delivering IT, they asserted that each model reflected a different stage of evolution of a school's IT, and this may be the case. The choice of the method of delivery has quite rightly been left to individual schools.

The arguments for abandoning all IT lessons are that:

- IT is placed in an appropriate context.

- An increased number of teachers become familiar with using IT.

- IT resources do not have to be centralized.

- Less pressure is put on an already overcrowded curriculum.

- In overcrowded schools there is less pressure on rooms.

- IT experiences are varied for the pupils.

The problems are:

- Coordination of IT is difficult, especially in respect to ensuring continuity and progression and assessment of pupil progress.

- Non IT staff may well not have IT skills and knowledge needed to deliver IT capability to their pupils.

- Classroom experiences may not relate to each other.

- Pupil attainment is dependent upon widely varying expertise and perhaps motivation of staff in subject departments.

- The status and control of IT staff may seem to be lost.

The sample of schools used was small but representative of all types of secondary school, and figures obtained concerning resources are similar to those published by the DFE [8], though the DFE figures do not include numbers of specialist IT teachers. The mean of 1.86 IT teachers in schools with an average size of 834 pupils must give rise to some concern regarding the delivery of IT capability no matter what mode of delivery is used. In reply to the question "How many specialist IT staff do you have in your school?" one coordinator replied, "one very tired and nervous wreck." 
The manner in which schools distributed IT lessons across the year groups varied, but the majority of schools (68\%) in the sample used some sort of mixed economy to deliver IT capability with few opting for either of the extreme models. The subject areas which were given some responsibility for delivering IT in most schools tended to be the core subjects and Technology, as the strands [4] map onto these more readily than some other subjects. However, the most worrying fact revealed in the survey was that $91 \%$ of IT coordinators reported dissatisfaction with the way IT capability is delivered by subject departments. This must mean that children are not receiving their entitlement. If the testing of Information Technology had occurred at the end of Key Stage 3, we may have had evidence to the contrary.

Most IT coordinators felt more timetabled IT lessons were required and these should be about $5 \%$ of the school week across all years.

At the time the research for this paper was being undertaken a review of the National Curriculum was taking place. Unfortunately, at the time of writing, only the consultation document 'Information Technology in the National Curriculum - Draft Proposals' [9] had been published. However, Dearing [10] recommends a time allocation of 45 hours per year in years 7 through 9 , with half of this time allocated to IT lessons and half to practising the skills learnt across the curriculum. This is very much a change from the suggestion made by the National Curriculum Council (NCC) that IT capability should be delivered entirely through other subjects. However, the proposed time allocated to IT lessons is approximately half that suggested by IT coordinators, but at least IT skills will be taught rather than acquired by osmosis [11]. For years 10 and 11 the School Curriculum and Assessment Authority (SCAA) [9] proposes that there are no IT lessons for all pupils and pupils should practice their IT capability in other subjects. This is counter to the opinion expressed by the majority of respondents to our survey.

However, though time allocations are less than suggested by our respondents, the content of IT capability has been reduced and this should ease pressures on staff, timetable and resources. The proposed reduction of IT capability has removed the 'Applications and Effects' strand [4] completely. Whilst this strand was possibly the one which caused most problems regarding delivery through other subjects, a very strong case could be made, in terms of teaching IT in context, for its retention.

The Dearing [10] and SCAA [9] proposals are moving in the direction suggested and followed by many of our respondents. However, major concerns still exist. 


\section{REFERENCES}

1. Birnbaum, I. (1989) IT in the National Curriculum - some fundamental issues. Resource Publication, Doncaster.

2. House of Commons (1988) Education Reform Act 1988: Chapter 40. HMSO, London.

3. DES (Department of Education and Science) (1990) Technology in the National Curriculum. HMSO, London.

4. NCC (1990) Non Statutory Guidance - Information Technology Capability. NCC. York.

5. Passey, D. and Ridgeway, J. (1991) Co-ordination of Technology does not Equal Co-ordination of Information Technology: misconceptions and maladaption. STAC, Lancaster.

6. Smith, M. (1991) Curriculum models for the effective delivery of Information Technology capability. Computer Education, 69, pp. 2-5.

7. Passey, D. and Ridgway, J. (1993) Implementing Information Technology in the Curriculum - A Guide to Secondary School Co-ordination - working Draft 9. Unpublished.

8. DFE (1993) Statistical Bulletin 6/93: - Survey of Information Technology in Schools. DFE, London.

9. SCAA (1994) Information Technology in the National Curriculum - Draft Proposals. HMSO, London.

10. Dearing, R. (1994) The National Curriculum and its Assessment. SCAA, London.

11. Kemmy, J. (1994) First, here is the good news. Times Educational Supplement Section 2, 27th May 1994, p. 19. 